\title{
Política de assistência social e trabalho social com família: autonomia ou maternagem?
}

Social welfare policy and social work with family: autonomy or motherhood?

\author{
Julietty Nunes Cardoso* \\ Solange Maria Teixeira **
}

\begin{abstract}
Resumo:
Com a intervenção do Estado Social, as funções de proteção social passam a ser públicas. Todavia, os países diferem nas características de seus sistemas de proteção social, conforme se dê a relação entre mercado, Estado e família, nessa proteção, e outras características políticas, econômicas e culturais. No atual contexto, a família constitui foco das políticas públicas, em especial da Política de Assistência Social, renovando-se as demandas pelo trabalho social com a família. $O$ objetivo deste artigo é problematizar, definir e analisar o trabalho social com famílias no âmbito do Serviço de Proteção e Atendimento Integral à Família - PAIF, por meio de pesquisa bibliográfica e documental.
\end{abstract}

Palavras-chave: Família; Políticas públicas; Trabalho social com famílias.

\begin{abstract}
:
With the welfare statesocial protection functions become public. However, countries differing the characteristic soft their social protection systems, as give the relationship between market, state and family that protection and other political characteristics, economic and cultural. The family is the focus of public policies, especially the Social Assistance Policy. The purpose of this article is to discuss, define and analyze the social work with families under the Protection Service and Customer Integral Family -PAIF, through bibliographical and documentary research.
\end{abstract}

Keywords: Family; Public policy; Social work with families.

\section{Introdução}

A família, ao longo da história da humanidade, tem assumido diferentes funções, entre elas a de proteção social de seus membros. Nas sociedades pré-capitalistas e na longa

\footnotetext{
* Assistente Social. Mestranda do Programa de Pós-Graduação em Políticas Públicas pela Universidade Federal do Piauí. E-mail: juliettync@hotmail.com

** Pós-doutorado em Serviço Social pela PUC-SP e Doutora em Políticas Públicas pela UFMA. Professora do Programa de Pós-Graduação em Políticas Públicas da Universidade Federal do Piauí. E-mail: solangemteixeira@hotmail.com
} 
fase do liberalismo, a família se constituía, embora não exclusivamente, na principal fonte de proteção dos indivíduos, e para os desvalidos, a proteção social da sociedade civil (mercado e organizações religiosas e filantrópicas).

Com o Estado Social, mediante políticas de corte social, as funções de proteção social passam a ser públicas. Na contemporaneidade, com as mudanças na regulação estatal e retorno dos ideais liberais, reatualizados e repaginados, a família assume a centralidade nas políticas sociais, em especial, na assistência social, o que fez surgir e reatualizar demandas por programas que tivessem como foco o trabalho social com famílias.

O objetivo deste artigo é discutir a centralidade da família nas políticas sociais e analisar o trabalho social com famílias, definido no Serviço de Proteção e Atendimento Integral à Família - PAIF, executado nos Centros de Referência de Assistência Social - CRAS, na proteção social básica da Política de Assistência Social, por meio de revisão bibliográfica e documental.

Para materializar esse objetivo, o artigo esta organizado em quatro partes. $\mathrm{Na}$ primeira, foram desenvolvidos os aspectos conceituais e históricos da família, além dos modelos de família brasileira e a relação com o patriarcado. Na segunda, apresenta-se a relação da família com os sistemas de proteção social e do Estado de bem-estar brasileiro. Na terceira, expõem-se as características da Política de Assistência Social e uma reflexão sobre o trabalho social com família na proteção social básica. Além de alguns aspectos como a responsabilização das famílias pelo cuidado de seus membros e, dentro dela, a mulher, pelos cuidados, proteção e socialização, o que acaba reforçando seus papéis tradicionais de mãe, cuidadora dos filhos e do lar. Finalizando, destacam-se os desafios do trabalho social com família, apontando pistas para repensá-lo e superar seus conservadorismos.

\section{Família: aspectos conceituais e históricos}

A família não é uma instituição natural, mas, sim, histórico-social, e a pluralidade de formas e modelos de vida familiar não é um traço contemporâneo. Antes da origem da propriedade privada já se percebia uma pluralidade de famílias. Quando a produção sai do centro da família, no capitalismo, com a mercantilização da força de trabalho e formação do mercado, ela deixa de ser espaço da produção, mas continua como espaço de 
reprodução social. A família, nessa ordem capitalista, passa a ser considerada unidade de consumo, além do espaço legítimo onde acontecia a procriação, a reprodução física, reprodução social e da manutenção da força de trabalho. Com o tempo, ocorreram mudanças não apenas no formato das famílias, mas, também, no que se refere aos papéis e valores.

Com isso, percebe-se que a família não é estável, ao contrário, é mutável e não pode ser naturalizada, deve ser também considerada como espaço de contradições, pois ao mesmo tempo que é lugar de proteção, também é de violação; é espaço de cooperação e solidariedade, mas também de desigualdades nas relações entre os gêneros e gerações.

Dessa forma, para Bruchini (1993), o primeiro passo para se analisar a família deveria ser diluir sua aparência de naturalidade, percebendo-a como criação mutável e observando que as relações entre o grupo conjugal e a rede de parentesco podem se apresentar como instituições bastante diferenciadas em outras sociedades ou em diferentes momentos históricos.

Autoras como Narvaz e Koller (2006) concebem a família como algo que não é biológico, algo natural ou dado, mas produto de formas históricas de organização entre os humanos. As diferentes formas de organização da família foram, portanto, construídas ao longo da história. Assim, uma das formas de organização foi centrada na figura masculina, a família patriarcal. No entanto, segundo as autoras, houve e ainda há outras configurações familiares, como as famílias matrifocais, matrilineares, centradas na figura e descendência feminina, e as monoparentais femininas contemporâneas.

No que se refere ao conceito de família, Mioto, Teixeira e Tavares (2011, p.108), além de extrapolar o modelo nuclear, biologista ou de parentesco, também a descreve como mutável, ou seja, como:

[...] um espaço muito complexo que se constrói histórica e cotidianamente através das relações e negociações que se estabelecem entre seus membros, entre ela e seus membros com outras esferas da sociedade, como o Estado, o trabalho e o mercado.

Entretanto, vários autores fundamentados em diferentes teorias, funcionalista, marxista, entre outras, definiram de forma diferente a família. Com base nessas definições de família e nos seus diferentes formatos, não se pode falar em apenas um conceito de 
família, nem em um único modelo, mas em famílias e numa pluralidade de conceitos. Os conceitos atuais, numa perspectiva crítica, a definem-na de forma ampla, extrapolando laços de parentesco e consanguinidade, pois muitas vezes essa é baseada na convivência, na afinidade, na construção de relações afetivas, de proteção e de cuidado duradouras. De fato, a família assume configurações diversificadas em sociedades ou grupos sociais heterogêneos; porém, o modelo de família nuclear só veio se consolidar por volta do século XVIII.

Nos séculos XVI e XVII, com a aristocracia, não havia divisão entre o público e o privado, assim, as famílias não se isolavam, pois viviam nas ruas e nas festas, não tinham as funções afetivas e socializadoras, visavam apenas à transmissão da vida, à conservação dos bens e à proteção da honra e da vida em caso de crise. Assim, essas famílias atribuíam pouco valor à privacidade, à domesticidade, a cuidados maternos, ao amor romântico e às relações íntimas com as crianças (BRUCHINI, 1993).

Com a ascensão da família burguesa, o padrão que passa a predominar é o emocional, definido pela autoridade dos pais, pelo profundo amor parental pelos filhos, uso de ameaças de retirada de amor, independência do casal das relações de parentesco, unidades familiares menores, com papéis fundados nas diferenças de gênero e na prioridade da força de trabalho masculina.

Esse modelo nuclear se torna hegemônico, adaptado às necessidades do capitalismo e é difundido para outras classes e frações de classes. Desse modo, conforme vai surgindo a aristocracia da classe trabalhadora, também emergem as primeiras conquistas trabalhistas, estendendo-se o esforço da burguesia filantrópica para reformar a moralidade da camada subalterna, integrando-a ao modelo de família burguesa (BRUCHINI, 1993).

Sobre a família nuclear, Parsons (1980), estudando a família norte-americana dos anos 1950-60, define suas principais características: diminuição da importância das unidades de parentesco; transferência de uma variedade de funções da unidade familiar ampliada para outras estruturas da sociedade, sobretudo os setores organizados por ocupações. Mas, isso não significou desfuncionalização ou perda da importância da família, no entanto essa se redefine. Ela, nessa sociedade urbana industrial, transforma-se em uma agência mais especializada. Destarte, isso demonstra uma tendência, o início de uma relativa estabilização de um novo tipo de estrutura familiar em uma relação nova, com uma 
estrutura social geral em que a família é mais especializada que antes, porém, não é menos importante em nenhum sentido geral (PARSONS, 1980).

A primeira característica que deve ser ressaltada em nível de organização de parentesco é o isolamento da família nuclear e sua relação com a bilateralidade respectiva das linhas de descendência. Este isolamento se manifesta nos membros da família nuclear, composta pelos pais e filhos; todavia, independentes, ocupam uma residência separada e não compartilhada com os membros da família particular de cada um dos cônjuges, e em que esta unidade familiar é economicamente independente, subsistindo em primeira instância nos rendimentos que ganha do esposo-pai do seu trabalho (PARSONS, 1980).

Por conseguinte, é possível observar a divisão de papéis sexistas, pois em geral se pode afirmar que o papel da mulher adulta não tem deixado de girar sobre os assuntos internos à família, como esposa, mãe e administradora do lar; e o papel do homem se volta para o mundo ocupacional, em seu emprego e mediante suas funções geradoras de posição e rendimentos para a família (PARSONS, 1980).

À luz dessas ponderações, deve-se destacar que Ariès (1981) já tinha caracterizado a família moderna nos séculos XVIII e XIX, considerando a família a partir da privacidade do par conjugal, do isolamento, e isso vai tornando-a menor. Porém, Parson (1980), mesmo sendo um funcionalista, associa essas mudanças às necessidades da nova ordem burguesa e que se generaliza, até os anos 1960, em grande parte do mundo capitalista.

Para esse debate sobre a consolidação da família nuclear, Ariès (1981) contribuiu com suas análises, ao discutir como vai se modificando a própria imagem da família extensa (seja a aristocrática ou a camponesa). Nas obras artísticas ou literárias pouco se retratava a ideia de casa, mostrava-se mais o ofício, a preocupação da família feudal do século XV era com a linhagem, pois os casamentos se davam a fim de evitar a divisão das fortunas; e era o primogênito que recebia a terra, acentuando a exclusão de outros filhos. Nas famílias abastadas entregavam as crianças para aprender um ofício (doméstico ou de uma profissão), para outras famílias.

O modelo nuclear descrito por Ariès (1981) e Parsons (1980) foi retratado como modelo ideal e hegemônico da sociedade burguesa, na qual a superestrutura jurídica e política buscou difundir e proteger, considerando como ilegítimos e ilegais as outras formas 
de vida familiar. Todavia, outros arranjos foram se multiplicando e lutando por reconhecimento.

Singly (2007), retratando a família contemporânea, ressalta as transformações que a afetaram, a partir dos anos 1960, no contexto da sociedade francesa, mas que pode ser expandido para famílias europeias e norte-americana nas últimas décadas, e em outras partes do mundo.

Ele a divide em primeira modernidade, caracterizada pelo laço afetivo mais forte, com a instituição do casamento por amor, a focalização nas relações interpessoais (no casal e desse para com os filhos), e a forte diferença nos papéis entre os sexos (mulher-mãe cuidadora e homem-pai provedor). A da segunda modernidade se caracterizou pela inserção maciça da mulher ao mercado de trabalho, lutas por direitos igualitários, em que a família se coloca a serviço dos membros, em que cada um se autonomiza, acentuando-se o individualismo e a autonomia dos sujeitos, mas não exclui e se contradiz com a vida familiar, porque esta agora a serviço desses indivíduos, e não o contrário.

Quanto à divisão sexual do trabalho, para Singly (2007), essa é funcional e se mantém, apesar das mudanças, pois na primeira modernidade as mulheres eram dependentes dos maridos; já na segunda, ela entra no mercado de trabalho e se autonomiza. Entretanto, a ela continuam recaindo os papéis clássicos de mãe e dona de casa, mas, também, o de provedora ou de complementação de renda pelo seu trabalho, ocasionando a dupla jornada de trabalho em que ela exerce as atividades laborais e ainda é responsável pelos trabalhos domésticos.

Contudo, as novas relações estabelecidas têm diminuído o valor atribuído ao casamento, aumentando as uniões estáveis; as pessoas permanecem nos relacionamentos apenas por amor, aumentando também as novas uniões após separações e divórcios; relacionamentos entre pessoas do mesmo sexo; casais sem filhos, entre outros modelos de vida familiar. Já são comuns as negociações de papéis e funções entre o par conjugal e a fuga do lugar comum estabelecido socialmente.

A manutenção das funções sexistas entre homens e mulheres tem sua origem na divisão sexual do trabalho posta pela família monogâmica e patriarcal, típica das sociedades de classes, na qual a opressão não é apenas classista, mas de gênero. Essa desigualdade de gênero é continuamente reproduzida no interior das famílias, pelo 
mercado, e nas formas de intervenção do Estado sobre os indivíduos e famílias, por meio das políticas públicas e especialistas.

\section{Famílias Brasileiras e o Patriarcado}

A família monogâmica tem origem patriarcal e decorre da propriedade privada. Essa, enquanto instituição na Roma Antiga, centrava-se no homem; o patriarca tinha sob seu poder a mulher, os filhos, os escravos e os vassalos, além do direito de vida e de morte sobre eles. Assim, a palavra família, em sua origem, não significa ideal; a princípio, entre os romanos, não se aplicava sequer ao par de cônjuges e aos filhos, mas somente aos escravos. Famulus significa escravo doméstico, família era o conjunto dos escravos pertencentes ao mesmo homem (ENGELS, 2006).

Define-se o patriarcado como uma forma de organização social na qual as relações são regidas por dois princípios básicos: no primeiro as mulheres são hierarquicamente subordinadas aos homens. E os jovens estão hierarquicamente subordinados aos homens mais velhos.

No que tange à família no Brasil, Álvares e José Filho (2008) mostram dois principais modelos familiares na história do Brasil e que fizeram parte do aparelho ideológico do Estado e do imaginário coletivo: o primeiro, a família patriarcal, que teve como referência o Brasil colonial, em que o chefe da família representava a figura do poder e de autoridade; o patriarca era responsável pelo controle dos negócios, sustento material e mantenedor da ordem familiar. Já a mulher tinha como atributos a afabilidade e mansuetude, com responsabilidades para o espaço doméstico. Deste modo, a posição da mulher, na família e na sociedade em geral, desde a colonização até hoje, demonstra que a família patriarcal foi uma das principais marcas de nossa organização social.

O segundo modelo é o da família burguesa, que surgiu no Brasil no início do século XX, com o processo de modernização, urbanização e industrialização. Esse se caracterizava pelo homem como maior autoridade do lar, o provedor econômico, responsável pela educação e o amor aos filhos; à mulher cabia o papel de boa mãe e esposa, administradora do lar e cuidadora dos filhos e do marido. Sendo assim, se o papel prescrito aos homens na família patriarcal e burguesa se pauta no sustento econômico, o papel dirigido às mulheres é o de que sejam cuidadoras do marido, dos filhos e do lar. Nessa perspectiva, o 
patriarcalismo se reatualiza e permanece sobre novas configurações e determinações na família burguesa, pois a origem de ambas é a monogamia, a dominação do homem que detém a propriedade privada.

Os estudos de famílias, de acordo com Scott (2005), destacam a forte influência da urbanização sobre a organização das famílias, o que indicou uma tendência para a diminuição do tamanho da família, a nuclearização dos grupos domésticos e o fim das famílias grandes tradicionais. Contudo, as famílias nucleares, não mais extensas, tornamse unidades pequenas e mais democráticas, que vão se adaptar melhor às condições urbanas.

A marca do patriarcado no Brasil pode ser observada também por meio das legislações, a exemplo, o Código Civil Brasileiro, de 1916, que foi patriarcal e paternalista, no qual a mulher casada só podia trabalhar com a autorização do marido. Só em 1934, com a nova Constituição, que as mulheres começaram a conquistar alguns direitos, como o voto feminino. Mais tarde, em 1941, o trabalho feminino foi regulamentado pela Consolidação das Leis Trabalhistas - CLT (NARVAZ; KOLLER, 2006).

Na ditadura de Vargas, os movimentos feministas são reprimidos e só voltam a ser retomados no início da 2a Guerra Mundial, quando os homens foram para a guerra e as mulheres tiveram que trabalhar para sustentar a família. O sistema de proteção social brasileiro, fundado a partir de 1930, fundamentava-se na modernização e na ampliação do emprego masculino, sendo necessário manter as funções das mulheres no lar e cuidado dos filhos. A mulher só era beneficiária do suporte social do trabalho masculino, na condição de dependente do marido (NARVAZ; KOLLER, 2006).

Só a partir do Código Civil Brasileiro de 1962 que mulheres casadas puderam trabalhar sem autorização do marido. Já o de 2002, estabelece que a família não seria mais regida pelo pátrio poder, mas pelo pater família, o que implica a igualdade de poder entre os membros do casal, no qual o termo todo homem foi substituído por toda pessoa. Com a $\mathrm{CF} / 88$, no seu art. 5ㅇ, assegura-se a igualdade entre homens e mulheres, em que trata dos direitos e garantias fundamentais. E o artigo 226 institui os direitos e deveres referentes à sociedade, exercidos igualmente pelo homem e pela mulher (NARVAZ; KOLLER, 2006).

Portanto, a família da segunda modernidade é vivida, no Brasil, a partir das últimas décadas do século XX, em que as mulheres são quase $50 \%$ da força economicamente ativa. 
Tiveram alguns direitos garantidos, como os direitos reprodutivos (direito do uso da contracepção), direito de constituir famílias sem cônjuges, de adotar crianças nessa condição, de acesso à proteção social pública, entre outros. Todavia, a permanência dos traços patriarcais, das assimetrias entre os gêneros, da tradicional divisão sexual do trabalho, das expectativas em torno do papel de mãe, dona de casa e da violência contra as mulheres ainda permanecem na cultura brasileira.

Nessa perspectiva, para Narvaz e Koller (2006), a cidadania estabelecida na Lei, não garante a cidadania substantiva, mulheres desconhecem seus direitos e seguem acumulando papéis, sendo sobrecarregadas com dupla jornada de trabalho, cuidado com a casa e com os filhos.

Ainda que o patriarcado seja anterior à chegada do capitalismo, esses dois sistemas parecem ligados na modernidade, pois são duas formas de produzir e de reproduzir a vida, a partir de relações de dominação e expropriação, em especial dos corpos e autonomias das mulheres. Nesse sentido, as várias formas de discriminação e de violência contra as mulheres são amostras das relações de poder historicamente desiguais. Denominadas violência de gênero, violação dos direitos das mulheres, ainda presentes nos diais atuais (NARVAZ; KOLLER, 2006).

Apesar da imperatividade do patriarcalismo, renovado nas relações capitalistas, agora regidos em nome do amor e da afetividade do casal e desse pelos filhos, a realidade é dinâmica e contraditória, com espaço de movimento para o diferente, para o novo, daí as mudanças e as vivências de novas relações, em meio à manutenção de outras, surgindo daí papéis familiares cotidianamente vividos de forma plural, heterogênea, criativa e subversiva.

Com efeito, a família é influenciada pela situação sociopolítica e econômica do país, em especial a brasileira, que ultrapassa em muito a noção de isolamento e unicidade. A dinâmica familiar é atingida pelas circunstâncias, bem como pelas formas de interferência do Estado. Essa intervenção pode manter as assimetrias de gênero e até contribuir para a sua manutenção e reprodução, como também para alterá-las, a depender do modo como é compreendido o papel da família e do Estado na proteção social.

\section{A relação família e a proteção social}


Anterior ao industrialismo, a família e a comunidade foram as primeiras instituições encarregadas pelo bem-estar social; posteriormente, as instituições da sociedade civil de origem filantrópica, religiosa ou patronal assumem a direção da proteção aos mais próximos. Com o advento da industrialização, a responsabilização da família e da comunidade é transferida para o Estado e o mercado. Nessa conjuntura, a família perde sua função de produção para o mercado, mas sempre permanecendo como parceira na proteção social dos seus membros, logo, na reprodução social.

No final do século XIX e início do século XX surgem as políticas públicas de proteção social, denominadas de Estado de Bem-Estar Social, que se apresentou de formas variadas nos diferentes países, dando origem a diversos regimes de bem-estar social. Nesta perspectiva, Esping-Andersen (1999) denominou os regimes de bem-estar, tomando como referência a relação entre Estado, família e mercado na provisão social. Quando o Estado assume a primazia na proteção social para todos os cidadãos de uma nação, ele age como um agente desmercadorizante e desfamiliarizante, tornando os cidadãos independentes do mercado e da família. Quando o Estado esta ausente ou age de modo insuficiente para cobrir os riscos sociais, ele sobrecarrega as famílias, denominado pelo autor de familismo.

De acordo com Esping-Andersen (1999), entende-se por familista a política social que vê a família como a principal responsável pela provisão do bem-estar dos seus membros, devendo o Estado intervir apenas de forma subsidiária ou quando se esgotarem as possibilidades de proteção pela família, como, por exemplo, a Itália e a Espanha que possuem um dos regimes com maior familismo, denominados de sistema mediterrâneo ou latino. Mas, também, o familismo pode ser compreendido pela não provisão do bem-estar social pelo Estado ou mercado, como pela inexistência de creches ou serviços para idosos; enquanto há países de regime de bem-estar social com acentuada "desfamilização", isto é, com maior grau de responsabilização do Estado ou mercado pela provisão do bem-estar social, que consequentemente fornecem serviços para a família, em especial, de cuidados para as crianças, casas de moradia, serviços para os idosos.

Assim sendo, de acordo com Esping-Adersen (1999), os únicos países de bem-estar social com maior grau de "desfamilização" foram Suécia, Dinamarca, no fim dos anos 1960, Noruega, Finlândia, Bélgica e França, no começo dos anos 1970, sendo os pioneiros em expandir serviços para a família. Dessa forma, como esses países oferecem serviços para a 
família, ou seja, possui uma política desfamiliarizante, isso contribui para independizar seus membros, principalmente as mulheres, ao passo que incentiva sua independência econômica e redução do tempo dedicado exclusivamente aos cuidados da família.

Todavia, os países que possuem políticas típicas do familismo, como Itália e Espanha, dificultam a entrada da mulher no mercado de trabalho e sua independência econômica, pois, além de não disponibilizarem serviços suficientes para as famílias, os serviços que o mercado oferece são inacessíveis, principalmente para os mais necessitados, ficando a cargo das famílias o bem-estar dos seus membros, em outras palavras, a cargo das mulheres. Desse modo, promove um aumento do trabalho doméstico não remunerado das mulheres, social e culturalmente responsabilizadas pelo cuidado dos membros dependentes da família.

Dessa forma, pode-se observar que grande parte dos regimes de bem-estar teve uma lógica familista. Outra autora que segue essa lógica é Zola (2013), que estuda as interrelações e extensões existentes entre a família e o Estado para o desempenho da proteção social.

Segundo Zola (2013), as alterações familiares decorrentes do ingresso da mulher no mercado de trabalho e da democratização das relações sociais vêm alterando a composição da família e sua dinâmica interna, o que afetou a proteção social. A interdependência do trabalho e a organização familiar podem ser notadas pela dificuldade da família, em especial a mulher, em harmonizar atividades familiares com o trabalho remunerado. Isso coloca em evidência, além da desigualdade de gênero, o forte comprometimento com a produção e reprodução, o que demanda mudanças culturais e a regulação do Estado para apoiar a proteção social de indivíduos e sociedade. Destarte, para a autora há uma tendência de centralidade na família para a proteção social de seus membros, que transfere atribuições e sobrecarrega as mulheres.

Para Esping-Andersen (1999), a maioria dos Estados de Bem-Estar Social ainda tem o viés da transferência de renda, e somente uma parte busca a redução de fato do encargo de bem-estar da família com serviços sociais. E, em grande parte, esses benefícios não são generosos o suficiente para as famílias pagarem pelos serviços no mercado, dado seu elevado custo, o que obriga as famílias a fazerem seus próprios serviços. Portanto, as famílias não foram desfuncionalizadas com o surgimento do Estado de Bem-Estar Social, 
aparecendo mais como parceira, mesmo nos regimes mais desfamilizantes, ou grandemente responsabilizadas nos mais familistas.

Ao caracterizar a Política familiar explícita, Zola (2013) cita o exemplo da Bélgica e da França, que apresentam um conjunto de programas de política social intencionalmente designados a alcançar finalidades específicas relacionadas ao bem-estar familiar e não às contribuições implícitas, como política de apoio a rendimentos, que também contribuem com a família, e são voltados ao combate a pobreza. Já os países do sul da Europa, Itália e Grécia, são fundamentados no modelo das solidariedades ou obrigações intergeracionais, - Estado desenvolve subsidiariamente a proteção social, uma política familiar implícita, mas não desenvolveu políticas de conciliação entre trabalho e família.

Já Mioto, Teixeira e Tavares (2011) destacam duas concepções de se pensar a relação família e proteção social. A primeira concepção entende a relação família e Assistência Social por meio da chamada ajuda pública ou intervenção pública, isto é, a família é a principal instância de proteção social e a Assistência Social só aparece no momento em que a família fracassa na provisão do bem-estar social para os seus membros. Isso, então, quer dizer que a relação entre Assistência social e família é intercedida pela ideia de falência, que se configura a partir de algumas questões, dentre elas, a incapacidade de a família buscar, gerir e otimizar recursos, inclusive e, principalmente, na sua relação com o trabalho e também com o reconhecimento de sua perda de capacidade, e desenvolver estratégias adequadas de sobrevivência e de convivência.

Outro ponto importante apontado por Mioto, Teixeira e Tavares (2011), da ideia de falência, é a crença na dificuldade da família em mudar comportamentos e estilos de vida, e também uma suposta incompetência de se articular em redes de solidariedade social. Nesse sentido, dessa falha de não ter capacidade para fazer tudo que pesa como expectativas sobre ela, surgem designações estigmatizantes, tais como "família disfuncional", "família patológica", "família desestruturada".

A segunda concepção se pauta no debate da relação família e Assistência Social, no campo dos direitos e da cidadania, ou seja, na perspectiva de que o Estado se constitui como instância principal de proteção social e, à medida que assume esse papel, possibilita a autonomia dos indivíduos, tornando-se força ativa no ordenamento das relações sociais. 
Dessa forma, a cidadania é atingida quando os direitos sociais, na prática e na legalidade, tornam-se invioláveis e universais (MIOTO; TEIXEIRA; TAVARES, 2011).

Nessa lógica, especialmente na década de 1990 e no Brasil, o Estado passa por reformas que se caracterizam pelas políticas neoliberais que impuseram ajustes dos países latino-americanos à nova ordem mundial, que tem como pressuposição a intervenção mínima do Estado na economia e restrita na área social para os mais pobres. Nesse sentido, o neoliberalismo implica medidas de restrições orçamentárias, mediante a diminuição com os gastos públicos, de privatização do Estado, o estímulo do setor privado por meio do aumento de suas ações e do apoio às iniciativas não lucrativas e de voluntários, substituindo até os serviços previdenciários estatais; o que tem contribuído para políticas sociais focalizadas, nas quais há o deslocamento dos gastos sociais para o combate à pobreza, e nos comprovadamente pobres, por meio de serviços sociais seletivos.

Nesse cenário, com a crise do Estado de Bem-Estar Social e o surgimento do neoliberalismo, a família reaparece com papel principal na proteção social e novas exigências recaem sobre ela, gerando graus elevados de comprometimento com o bemestar, uma vez que a ação do Estado na política social é reduzida e o mercado se volta para a satisfação das necessidades lucrativas.

No Brasil, a política dirigida à família, mesmo que ofereça proteção, o faz para que possa proteger seus membros, o que reforça suas funções protetivas e a dependência do indivíduo das relações familiares, fortalecendo o familismo, ao invés de ser desfamiliarizante. Além disso, sua rede de serviços é subdesenvolvida, face aos benefícios, e atua sempre no sentido de impulsionar as funções familiares na proteção, tidas como insubstituíveis, ampliando ainda mais as pressões sobre as inúmeras responsabilizações que devem assumir, especialmente no caso das famílias pobres e vulneráveis (TEIXEIRA, 2013).

Apesar do reconhecimento das transformações familiares, que impactam na sua capacidade de proteção, a política pública convoca a família e a proclama como parceria privilegiada para o desempenho da proteção social. Assim sendo, a família passa a ter sua função renovada, já que de um lado cresce a inoperância do Estado como provedor do bem-estar e, de outro, as possibilidades de o mercado e a sociedade civil assumirem essa 
provisão. Nessa perspectiva, programas sociais são criados, tendo como foco a família, e o trabalho social dirigido a ela é demandado, partindo da implementação desses programas.

\section{O trabalho social com família na política de assistência social}

A Política de Assistência Social teve sua tradição histórica voltada ao assistencialismo e à benemerência, e só com a Constituição Federal de 1988 passa a ser concebida como um direito social. Nessa política, a família é definida nas suas legislações e programas, em especial na Política Nacional de Assistência Social (PNAS), que tem como princípio a matricialidade sociofamiliar, cujo fundamento é a centralidade na família, além do pressuposto de que a família pode prevenir, proteger e promover e incluir seus membros, só que para isso precisa de meios para desempenhar essas funções (BRASIL, 2004).

A NOB/SUAS define a matricialidade sociofamiliar e a territorialização como um dos eixos estruturantes da gestão do Sistema Único de Assistência Social. Esses eixos significam que a assistência social dá "primazia à atenção à família e seus membros, partir do território de vivência, com prioridade àquelas com registro de fragilidades, vulnerabilidades e presença de vitimação entre seus membros" (BRASIL, 2005, p. 28).

O eixo da matricialidade sociofamiliar, por trazer a família como centro, pode acarretar certos conservadorismos, como responsabilizar a família pelo cuidado de seus membros e, dentro dela, a mulher, pela falha nos cuidados, proteção e socialização, o que acaba reforçando seus papéis tradicionais de mãe, cuidadora dos filhos e do lar. Além disso, a busca pelo retorno dos padrões da família nuclear tradicional, considerado ideais, mesmo a política de assistência reconhecendo os diversos modelos de família, espera dos mesmos um padrão de funcionalidade típico da família nuclear constituída por pai, mãe e filhos (TEIXEIRA, 2010).

Outro retrocesso em relação a esse eixo se refere à psicologização da realidade das famílias, isto é, focalizam-se as suas características psicológicas, como resgatar e fortalecer vínculos familiares em detrimento da dura realidade socioeconômica dessas famílias. Além da reprivatização do cuidado social como dever de cada família e, dentro dela, a mulher, como forma de ocultar a responsabilidade do Estado em prover serviços de qualidade e que atendam à demanda das famílias, principalmente da mulher, de forma que o Estado possa oferecer serviços para os membros dependentes, possibilitando assim a liberação do 
tempo para investimento em outros projetos pessoais, para qualificação profissional, para trabalhar e ter independência financeira (TEIXEIRA, 2010).

A literatura especializada sobre a relação família e políticas públicas tem mostrado que essa centralidade da família na Política de Assistência Social vem reforçando o familismo das políticas sociais, ou seja, o reforço das suas responsabilidades e até a ampliação dessas, pela proteção, cuidados e assistência aos seus membros, e que o trabalho com famílias tem reproduzido essa máxima, naturalizando os papéis da família e contribuindo para a manutenção da maternagem como função das mulheres, portanto, mantendo a tradicional divisão sexual do trabalho no âmbito da família.

Nessa perspectiva, o Estado e as organizações de assistência social (organizações não governamentais) seriam os responsáveis em prover os meios para que a família pudesse desenvolver suas funções. Mas, o que mostram vários estudos, é que na prática o que ocorre é a responsabilização da família com a proteção social dos seus membros, dada a ausência ou precarização e insuficiência dos serviços de inclusão social, tanto públicos como de organizações não governamentais, que formam a rede socioassistencial.

$\mathrm{Na}$ atual conjuntura de reformas, o Estado não mais reivindica o posto de condutormor da política social, pelo contrário, dele se afasta. O mercado, por sua vez, nunca teve vocação social e, por isso, a despeito de praticar a filantropia como estratégia de marketing, prefere aprimorar-se na sua especialidade, que é a de satisfazer preferências, visando ao lucro e não às necessidades sociais. Desse modo, Estado e mercado cedem cada vez mais espaço à sociedade, em especial, à família.

Logo, o pluralismo de bem-estar social tem como um dos seus objetivos o retorno da família, organizações não governamentais e mercado enquanto fontes privadas de proteção social, com participação ativa nos modelos de proteção social de viés neoliberal.

Numa perspectiva inversa a essa, esta um grupo que luta por maior proteção social e responsabilização do Estado, que considera, mediante as transformações na família, sua vulnerabilidade, pobreza e dificuldades para lidar com os conflitos e demandas de proteção social contemporâneos; a necessidade de essa ser tomada como sujeito de direitos, o direito a ser incluída na rede de proteção social pública, portanto, alvo das políticas públicas. Essa tendência luta por serviços sociais para a família, que possam diminuir as 
responsabilidades familiares, liberando a mulher para o trabalho, incluir filhos e idosos em serviços diurnos para preservar o fundamental, a existência do grupo familiar.

Com a ausência de um eficaz Estado de Bem-Estar Social, em que se pode perceber uma deficiência na oferta de serviços públicos e baixos salários, como no Brasil, a família se apresenta como "parceira" do Estado, atuando numa lógica de solidariedade, como grupos de formação e distribuição de renda e consumo, de cuidados e assistência, garantindo assim a reprodução de seus membros.

Sob a análise da trajetória histórica da Política de Assistência Social, é importante observar que ela esta intimamente ligada ao trabalho com famílias. No entanto, a família, em especial a família pobre, na maioria das vezes era considerada incapaz de cuidar e proteger sua prole, além de culpabilizada pelos problemas que atingiam seus membros, ou seja, a família era constitutiva do problema social e de que seus responsáveis não tinham a capacidade de educar crianças, proteger seus membros da marginalidade. $\mathrm{O}$ trabalho social se direcionava aos segmentos (crianças, adolescente, idosos, deficientes) e tinha a marca da institucionalização (MIOTO, 2004).

De fato, historicamente, na assistência social o trabalho social com famílias as considerava irregulares, desestruturadas, por causa de seus modelos de família. Sobre elas recaía um trabalho normativo, moralizador, individualizante e integrador, fundamentado no paradigma da patologia social e com os recursos terapêuticos do trabalho psicossocial individualizante, e dentro desse trabalho as mulheres devem cumprir condicionalidades e são culpabilizadas pelas falhas no cuidado e na socialização da família (MIOTO, 2010).

Sobre essa questão, Narvaz e Koller (2006) apontam que a impossibilidade de cumprir com a maternidade normativa (ou com a maternagem) é atribuída a uma falha individual, descolada do contexto histórico e social que a produziu, como a pobreza, falta de suporte conjugal, comunitário e social. Resquício do tradicionalismo imposto pela ordem capitalista patriarcal. Esse discurso desobriga os homens, o Estado e a comunidade de sua responsabilidade social.

O trabalho social com famílias na proteção social básica da assistência social reflete a forma de incorporação da família na política e, em muitos casos, apesar de afirmarem como de objetivos de emancipação, autonomia e empoderamento das famílias, podem 
indicar sentido inverso, de reforço da maternagem, da tradicional atribuição das mulheres à função de cuidados, ao reforço das funções clássicas das famílias, entre outras.

Com base nas considerações supracitadas, o trabalho social com famílias também se modifica a partir de novas legislações, como a PNAS e SUAS, que vêm trazendo novos fundamentos para esse trabalho na proteção social básica, em especial nos Centros de Referência da Assistência Social, nos quais o PAIF é o principal serviço.

Esse serviço tem caráter continuado e visa fortalecer a função protetiva das famílias, prevenindo a ruptura de seus vínculos e prevê, em suas normativas, o trabalho social com famílias, individualizado ou em grupo, e o acompanhamento das famílias, em especial àquelas em situação de maior vulnerabilidade, como nos casos das famílias em descumprimento das condicionalidades do Bolsa Família, entre outras.

O Documento sobre "Orientações Técnicas sobre o PAIF", volume 1, estabelece os objetivos do serviço: "prevenir situações de risco social, por meio do desenvolvimento de potencialidades e aquisições e do fortalecimento de vínculos familiares e comunitários" (BRASIL, 2012, p. 10). Sua atuação é de forma preventiva, protetiva e proativa e "sua função é 'apoiar' a família no desempenho de sua função protetiva, num dado território, caso as famílias tenham o desejo de fortalecer sua capacidade protetiva" (BRASIL, 2012, p. 13). Logo, esse trabalho com famílias do PAIF não tem como objetivo "obrigá-las" a cumprir tal papel protetivo.

Destarte, elencar como uma primeira função o reconhecimento e fortalecimento dessa função protetiva não é valorizar a família, mas, sim, culpabilizá-la pelas situações de vulnerabilidade, que com certeza são decorrentes de múltiplos fatores, em que a dinâmica familiar é apenas um deles e não o principal. Assim sendo, o PAIF tem como um de seus objetivos reforçar o papel protetivo da família, o que se caracteriza como um retrocesso, pois retorna o problema e o trata internamente na família ou, quando muito, ajudá-las a utilizar seus recursos nessa direção. O poder público deveria ser uma alternativa para a resolução dos problemas que as famílias enfrentam, para evitar as rupturas dos vínculos e garantir a convivência familiar e comunitária. Quando a política pública toma como tarefa fortalecer a função protetiva da família, ela se exime de ser mais um mecanismo de enfrentamento dos problemas que afligem as famílias, mediante serviços, benefícios e trabalho educativo que vise à inclusão social. 
Essa contradição se soma a outras expressas na ideia de reconhecer e fortalecer potencialidades, de que as famílias, mesmo em situação de vulnerabilidade, têm ativos, capacidades que devem ser reconhecidas e incentivadas. Assim, o documento destaca:

\begin{abstract}
Proteção que além do enfrentamento das vulnerabilidades e riscos sociais, atua também no "desenvolvimento de potencialidades", a partir do reconhecimento de que ninguém está desprovido de tudo: uma família que está sobrevivendo na vulnerabilidade detém ativos importantes. Nessa direção é preciso identificar e fortalecer os recursos disponíveis das famílias, suas formas de organização, participação social, sociabilidade e redes sociais de apoio, entre outros, bem como dos territórios onde vivem (BRASIL, 2012, p. 11).
\end{abstract}

É clara a lógica de parceria entre Estado e família, não numa perspectiva complementar, subsidiária à intervenção pública, mas numa lógica de equitatividade nos níveis de proteção social e até da valorização do segundo como o mais eficiente, porque é movido pela lógica afetiva, dos vínculos. Trata-se de um desmonte da proteção pública, da ruptura com a lógica do direito e do enfrentamento público dos problemas sociais, individualizados em caso a caso e devolvido para o trato privado no âmbito das famílias, deixadas a sua própria sorte diante de problemas que não têm capacidade de resolver, pois é exatamente essa situação que as caracterizam como vulneráveis.

A capacidade das famílias vulneráveis é interpretada como um espartilho que pode ser esticado ainda mais, posto que as famílias usuárias do PAIF detêm de ativos importantes, como as normativas. Todavia, os usuários do serviço são "famílias em situação de vulnerabilidade social decorrentes da pobreza, do precário ou nulo acesso aos serviços públicos, da fragilização de vínculos de pertencimento e sociabilidade e/ ou qualquer outra situação de vulnerabilidade ou risco social" (CONSELHO NACIONAL DE ASSISTENCIA SOCIAL, 2009, p.7). O que significa que ela necessita de meios para garantir a proteção social dos seus membros, que deveriam ser oferecidos pelo poder público de forma preventiva para que elas não chegassem a vivenciar as situações de riscos.

O trabalho social com famílias na proteção social básica reflete a forma de incorporação da família na política, uma forma contraditória, mas que também tem objetivos de emancipação, autonomia e empoderamento das famílias. Para isso, são definidas algumas ações a serem executadas no âmbito do PAIF, para materializar seus objetivos, já que é preciso sempre associar sua realização aos escopos do serviço que se 
pretende alcançar, garantindo seu efetivo cumprimento. São ações: acolhida; oficinas com famílias; ações comunitárias; ações particularizadas; encaminhamentos.

Deste modo, o PAIF tem priorizado ações que enfatizam o trabalho socioeducativo. Esse pode ter efeitos emancipatórios ou reprodutores da ordem e das relações de gênero. Nesse segundo caso, ocorre quando as ações se voltam para as questões internas à família, no sentido de determinar habilidades para o cuidado doméstico, para o reforço de responsabilidades familiares, a priori, de novos conhecimentos adquiridos e da discussão e reflexão do seu cotidiano. Nessa dimensão, o trabalho social com famílias, a partir de métodos educativos, preserva a herança da educação disciplinadora e normatizadora da família, que assume faces modernizadoras que camuflam sua dimensão normativa (TEIXEIRA, 2012).

Destarte, as orientações técnicas do PAIF podem direcionar-se para uma dimensão conservadora do trabalho social com família. Todavia, verifica-se potencialidade do trabalho social nos CRAS, em especial, com grupos, nos quais podem ser redirecionados à compreensão da sua realidade e à busca de soluções coletivas. Nessa perspectiva, o trabalho nos CRAS pode se ampliar como antídoto à sua transformação em serviço cartorial, de cadastramento, recadastramento, de encaminhamentos, e se transformar em espaço de oferta de serviços de suporte à família e seus membros com serviços de orientação, informação, conscientização sobre direitos, modos de acessá-los e garanti-los, sobre suas dificuldades cotidianas (TEIXEIRA, 2012).

O PAIF, em suas ações também ressalta que é necessário promover aquisições sociais e materiais às famílias, potencializando o protagonismo e a autonomia das famílias e a comunidade. Nesse sentido, Teixeira (2012) destaca que é necessário superar a noção de autonomia voltada à dimensão liberal, individual e subjetivista, como forma de ensinar os usuários a "andar com as próprias pernas", de cuidar sozinhos dos filhos e seus dependentes, de resolver conflitos familiares por meio de processos profissionais que fortaleçam a autoestima e que capacite para o cuidado e responsabilidades familiares. A autonomia social é aquela que visa gerar novas subjetividades políticas, capacidade de análise da realidade e de dimensionar as soluções imediatas e mediatas.

As ações previstas no PAIF, que instrumentalizam o Trabalho Social com Famílias são um importante recurso que profissionaliza o campo da assistência social, uma área que 
historicamente foi marcada pelo assistencialismo, ações dispersas, fragmentadas, descontínuas e realizada de forma imediata. Isso coloca a assistência social numa dialética de avanços e conservadorismos.

\section{Considerações finais}

A relação Estado/família é uma via de mão dupla, além disso, a intervenção do primeiro nunca eliminou as responsabilidades familiares, especialmente no Brasil; antes, ao contrário, sempre requer cumprimento de responsabilidades ou cria novas responsabilidades. As novas relações Estado/família num contexto de restrição de gastos sociais e avanço do neoliberalismo implicam a ampliação dessas responsabilidades e nos levam a questionar se de fato a família esta sendo incluída na política social numa perspectiva de direitos, já que sempre se exige contrapartidas, cumprimento de condicionalidades. A raiz dessas condicionalidades, centradas nos papéis clássicos da família, e da mulher cuidadora, são as relações burguesas patriarcais. O trabalho com famílias nessas políticas, em especial da assistência social, não consegue superar a perspectiva normatizadora que fortalece essas relações assimétricas entre os gêneros.

Em contraposição a essa perspectiva, o Estado deveria ofertar serviços que visem ao protagonismo, à autonomia e contribuam para a participação social e política das famílias, que objetivem a emancipação, superação da subalternidade com ações que as reconheçam como sujeitos de direitos.

O trabalho social com famílias deve ser fundamentado na autonomia e no protagonismo social, ou seja, oferecer condições para que os sujeitos possam valorar, intervir, avaliar, escolher, agir conscientemente. Os profissionais que desenvolvem esse trabalho devem pautar-se em uma postura crítica, já que visa ao protagonismo de seus usuários, e esse não pode ser entendido fora do quadro de luta por seus direitos de cidadania (TEIXEIRA, 2010).

Deste modo, para Teixeira (2010), é necessário atuar no encorajamento da participação social dos usuários, o que remete a trabalhar numa perspectiva de ampliação de seu universo informacional, criando espaços de debates, aprendizagens, socialização de informações, uma atmosfera de trocas e que facilite a expressão pessoal dos usuários, de forma a superar as ações disciplinadoras. 
Assim, a inclusão social na rede de serviços públicos é a única via possível de prevenção e resolução dos problemas sociais, na ordem capitalista, para isso é preciso o protagonismo do Estado na oferta de serviços e trabalho socioeducativo baseado na lógica do direito.

\section{Referências}

ÁLVARES, L. C; JOSÉ FILHO, M. O serviço social e o trabalho com famílias. Serviço Social \& Realidade, Franca, v. 17, n. 2, p. 9-26, 2008.

ARIÈS, P. As imagens da família. In: . História social da criança e do adolescente. Tradução de Dora Flaksman. 2. ed. Rio de Janeiro: LTC, 1981. p. 131-196.

BRASIL. Ministério do Desenvolvimento Social e Combate à Fome. Política Nacional de Assistência Social (PNAS). Brasília: MDS/SNAS, 2004.

. Ministério do Desenvolvimento Social e Combate à Fome. Norma operacional básica da assistência social: NOB/SUAS. Brasília: MDS\SNAS, 2005.

. Ministério do Desenvolvimento Social e Combate à Fome. Orientações sobre o PAIF, v. 1, 2012. Brasília: MDS, 2012b. v. 1, p. 1-78.

BRUCHINI, C. Teoria crítica da família. In: AZEVEDO, M. A.; GUERRA, V. N. de A. (Org.).Infância e violência doméstica: fronteiras do conhecimento. São Paulo: Cortez, 1993.

CONSELHO NACIONAL DE ASSISTÊNCIA SOCIAL. Tipificação nacional de serviços socioassistenciais: resolução no 109, de 11 de novembro de 2009. Brasília: MDS: 2009.

ENGELS, Friedrich. A origem da família, da propriedade privada e do Estado. Tradução Ruth M. Klaus. 3 ed. São Paulo: Centauro, 2006.

ESPING-ADERSEN, G. A economia da unidade familiar doméstica. In: Social foundations of pos-industrial economies. New York: Oxford, 1999. p. 47-70.

MIOTO, R. C. T. Trabalho com família: um desafio para os Assistentes Sociais. Revista Virtual Textos e Contexto, Porto alegre, ano 3, n. 3, p. 1-15, dez. 2004.

. Família: trabalho com famílias e Serviço Social. Serviço Social em Revista, Londrina, v. 12, n. 2, p. 163-176, 2010.

A família como referência nas políticas públicas: dilemas e tendências. In: TRAD, L. A. B. (Org.). Família contemporânea e saúde: significados, prática e políticas públicas. Rio de Janeiro: Fiocruz, 2010. p. 51-60. 
MIOTTO, R. C. T.; TEIXEIRA, M.; TAVARES, M. H. Família, gênero e assistência social. In: CONSELHO FEDERAL DE SERVIÇO SOCIAL. O trabalho do assistente social no SUAS: Seminário Nacional. Brasília: CEFESS, 2011. p. 108-117.

NARVAZ, M. G; KOLLER, S. H. Famílias e patriarcado: da prescrição normativa à subversão criativa. Psicologia e Sociedade, Porto Alegre, v. 17, n. 1, p. 49-55, 2006.

PARSONS, T. La família em La sociedad urbana-industrial de lós Estados Unidos. In: ANDERSON, M. (Org.) Sociologia de lafamilia. México: Fondo de Cultura Económica, 1980. p. 41-59.

SINGLY, F. de. Sociologia da família contemporânea. Tradução de Clarice Ehlers Peixoto. Rio de Janeiro: FGV, 2007.

SCOTT, P. A família brasileira diante de transformações no cenário histórico global. Revista Anthropológicas, Recife, ano 9, v. 16, p. 217-242, 2005.

TEIXEIRA, S. M. Trabalho social com famílias na política de Assistência Social: elementos para sua reconstrução em bases críticas. Serviço Social em Revista, Londrina, v. 13, n. 1, p. 4-23, jul./dez. 2010.

A centralidade da família nas políticas sociais e o trabalho social com famílias. In: ENCONTRO NACIONAL DE PESQUISADORES EM SERVIÇO SOCIAL, 13., 2012,Juiz de Fora. Anais... Juiz de Fora, 2012.

Trajetória da família no sistema de proteção social brasileiro: do enfoque difuso à centralidade na política de assistência social. In: . A familia na política de assistência social: concepções e as tendências do trabalho social com famílias nos CRAS de Teresina-PI. Teresina: EDUFPI, 2013. p. 74-79.

ZOLA, M. B. P. S. Família e proteção social: um estudo acerca das políticas familiares em diferentes cidades e países. In: MIOTO; R. C. T; CAMPOS, M. S.; CARLOTO. C. M. (Org.). Familismo, direitos e cidadania: contradições da política social. São Paulo: Cortez: 2013. p. 32-68. 